
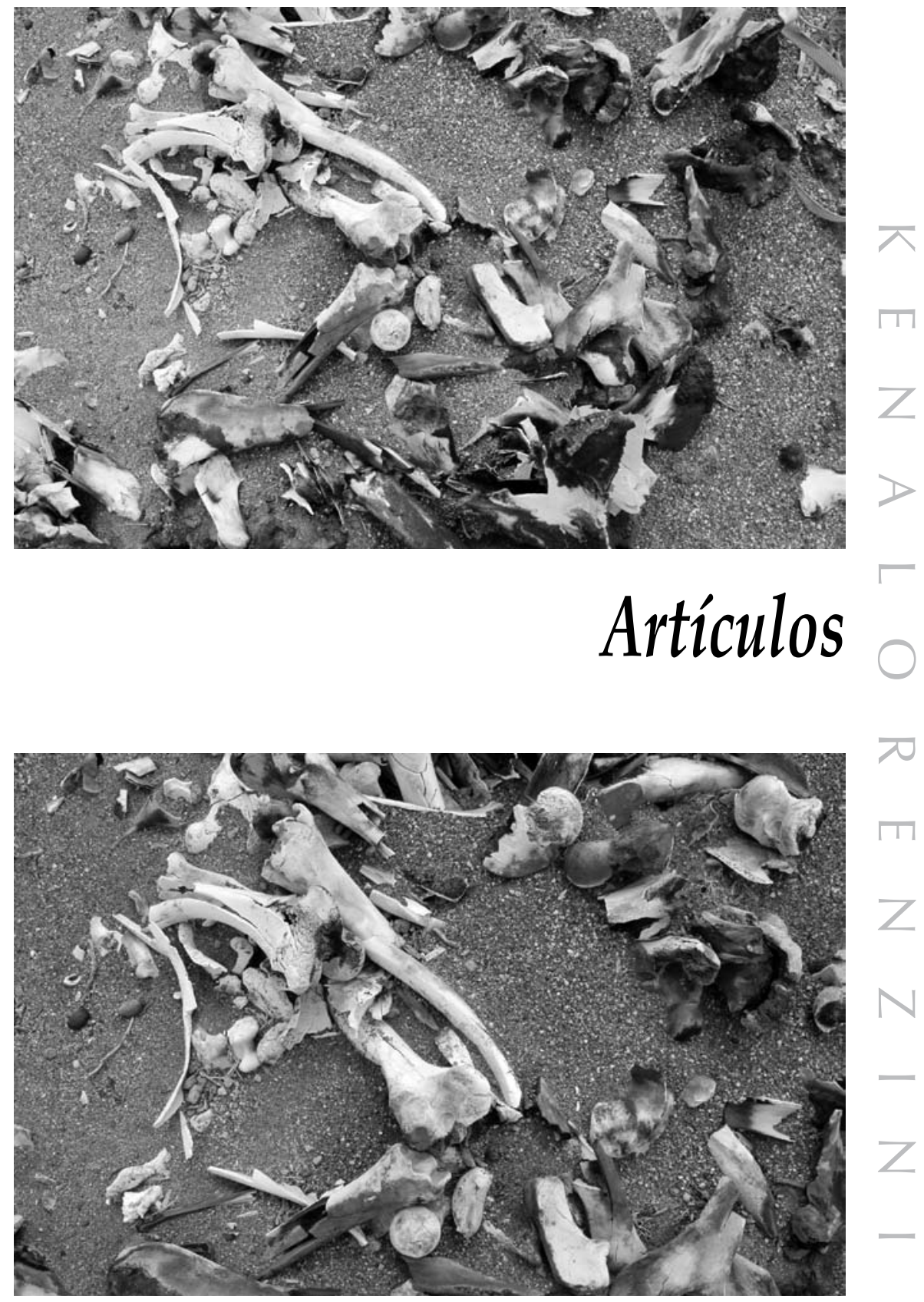

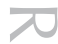

II

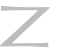

V 


\title{
Nuevas violencias contra las mujeres
}

\author{
María Luisa Femenías ${ }^{1}$
}

\begin{abstract}
SÍNTESIS
La violencia contra las mujeres tiene múltiples facetas. En los últimos años parece incrementarse lo que se ha dado en llamar "violencia doméstica", aumentando significativamente los indices en las capas medias y medias altas de la sociedad. Este breve artículo examina sus posibles causas específicas y las vincula a los desafíos de la globalización en relación a la autoestima de los varones. Este artículo debe leerse también sobre el transfondo de una hipótesis general que abarque la violencia física, la moral, la psicológica y por supuesto la del lenguaje.
\end{abstract}

\section{ABSTRACT}

Violence against women is multiple. Recently, "domestic violence" has increased specially among middle class and high middle class. This short article intends to analyze a cluster of causes related to globalization and man selfrespect as "breadwinner" and head of the family. We learn of this kind in comparison to physical, moral, psychic and linguistic violence.

Palabras clave: Violencia - globalización - identidad - autoestima.

Key words: Violence - globalization - identity - selfrespect.

\section{1- Leer el periódico}

ALARMANTE RELEVAMIENTO SOBRE FEMICIDIO EN...:

Una mujer es asesinada cada tres días. En 2008, se registraron 105 crímenes de mujeres cometidos por sus parejas, contra 95 casos de 2007 y 68 difundidos en 2006. En lo que va de 2009, la cifra de la violencia de género asciende a 38 muertes. La mayoría de las victimas no supera los 24 años (Crítica,2009, 4-5).

En los últimos meses, esta noticia (o similares) ha recorrido el país, de la mano de muchos periódicos, incluidos los de circulación nacional, muchas veces en letras catastróficas y con las modificaciones propias del perfil editorial de cada publicación. 
Basta echar una rápida mirada a otros periódicos, publicados más allá de nuestras fronteras, para comprobar que se trata de una situación extendida. En apariencia, a pesar de que los hechos han sucedido en diferentes lugares y en diferentes países, clases sociales, marcos culturales y económicos, guardan grandes semejanzas en lo que -sin pretensiones técnicas- podemos denominar el modus operandi de los perpetradores. En todos y en cada caso, prima una violencia extrema, excesiva, ensañada, desbordada, como sus rasgos más característicos, a lo que se suele sumar la pertenencia próxima al entorno de las víctimas. Entre quienes ostentan la voluntad de indistinción como su mejor arma, se suele denominar a esos crímenes "pasionales" o perpetrados bajo "emoción violenta", considerándose tales rótulos argumentos explicativos suficientes. La crónica periodística se complace en subrayar -como dato no menor (e insuficientemente estudiado)- que en la mayoría de los casos se trata de agresores varones pertenecientes al núcleo más próximo de la víctima: un (ex)marido, (ex)novio, (ex)compañero sentimental (como se suele decir ahora), (ex)pareja o (ex)amante, un padrastro, tío, abuelo, etc. Una suerte de regodeo mediático se desata ante la intimidad familiar de víctimas y victimarios, donde las explicaciones más frecuentes son los celos, el despecho, la venganza a los que, por supuesto, se añade una fuerte cuota de dudas "razonables" sobre la moralidad de las víctimas. Cuando se trata de niñas, las opiniones generales se avalan con la teoría freudiana de la seducción infantil, salvo que se trate de niñas muy pequeñas, en cuyo caso se suele apelar a la piedad de las lágrimas fáciles.

En esta presentación, quiero compartir algunas reflexiones, aún incompletas, con el objetivo de discutir otras variables e hipótesis explicativas para echar algo más de luz sobre un fenómeno que corre el riesgo de convertirse en una "normalidad" cotidiana más, de las demasiadas a las que nos estamos malacostumbrando. En primer lugar, recordaré de manera somera el marco general desde el cual abordo el problema de la violencia contra las mujeres, luego aportaré algunas líneas tendientes a elaborar una propuesta explicativa para un conjunto de hechos violentos y, por último, esbozaré algunas conclusiones que, dado el carácter provisional de estas reflexiones, guardarán el mismo tenor. Quiero destacar que en un problema tan grave como este, no se pueden extraer conclusiones definitivas $y$, menos aún, 
ofrecer recetas y soluciones globales inmediatas. Solo se puede, con mucho cuidado y sistemáticamente, separar capas de significados y redes conceptuales a fin de favorecer una mejor comprensión y planteamiento del problema, tratando de desenmarañar el complejo ovillo de concausas.

\section{2- Hacia un marco comprensivo}

Según la socióloga española Raquel Osborne, solo recientemente se ha comenzado a desentrañar el problema de en qué consiste la violencia de género, y a disponer de un corpus significativo de datos y bases estadísticas y teóricas para una reflexión crítica que permita elaborar unos marcos comprensivos y explicativos del problema $(2008,99) .{ }^{2}$ Precisamente uno de los grandes logros del feminismo contemporáneo es que cambió nuestra comprensión de la sexualidad, de las relaciones entre mujeres y varones, vinculando la violencia sexual contra las mujeres como un mecanismo que pretende mantenerlas en la subordinación en la que históricamente han estado. El desvelamiento de los factores de poder intervinientes, la creación de recursos, el esclarecimiento que han alcanzado las mismas mujeres sobre sus derechos a pesar de los modos sutiles en que muchas veces aún quedan entrampadas es mérito del trabajo sostenido de muchas militantes y teóricas de distintas áreas y competencias disciplinares, en diversos países; todas, por cierto, con la voluntad de individualizar y precisar las múltiples variables que intervienen en los diversos procesos de violencia contra las mujeres, a fin de encontrar los modos de comprenderla, desmontarla, y remediarla.

Contrariamente a la voluntad de indistinción, que parece primar en algunos discursos, muchas teóricas consideramos que la compleja diversidad de concausas, que converge en las situaciones de violencia, merece ser identificada y examinada minuciosamente porque -creemos- no hay solución posible sin un buen planteo del problema, y el de la violencia no es una excepción. Con estas líneas generales presentes, mi interés es contribuir a la profundización de esas reflexiones.

En principio, diferencio, para este trabajo, entre "violencia" y "fuerza". Como tantos otros, "fuerza" es también un término polisémico. Al menos en uno de sus significados -que es el que 
me interesa ahora-, puede entenderse "fuerza" como "conforme a legalidad", en el sentido de "la fuerza de la ley" o "la fuerza de la razón". En cambio, "violencia" siempre hace referencia a una acción que es externa o ajena a la legalidad, como mostré en otros trabajos (Cf. nota 2). Aunque para otros problemas, Jean Paul Sartre observó agudamente que la "violencia" tiene lugar precisamente alli donde la "fuerza" es ineficaz. ${ }^{3}$ En ese sentido, la violencia -que es siempre un desborde- se ejerce sobre los organismos vivos, los útiles, los asentamientos humanos y los seres humanos. Desde un punto de vista feminista, se la ejerce paradigmáticamente y primero sobre los cuerpos de las mujeres $\mathrm{y}$, segundo, sobre los cuerpos en situación de feminización; ambos constituyen el "ahí" de la violencia de sexo-género.

Ahora bien, entiendo "legalidad" en un sentido amplio, que incluye la Ley (en términos ético), las normas (morales), los estilos consuetudinarios, que suelen ser referidos como "usos y costumbres" (o "moral y buenas costumbres"), incluso, las "tradiciones" normalizadas y, por supuesto, las leyes del Estado. En otras palabras, lo que constituye el entramado del afuera, con sus diferentes espesores y densidades. Cuando la legalidad que implica el disciplinamiento - en el sentido explicitado- no basta, la violencia es $\mathrm{el}$ modo privilegiado de acceso o de logro de ciertos fines.

Antes de proseguir, quiero llamar la atención sobre el hecho mismo de la pregunta por la posibilidad de desmontar (o deconstruir) la violencia de sexo-género. Para formular esta pregunta ha sido preciso que previamente se despejaran las condiciones de "naturalidad" de todas las normas consuetudinarias de comportamiento y denunciarlas como "leyes positivas". Es decir, subrayo que han dejado de ser auto-evidentes e incontestables para nuestra vida en sociedad, que se ha debido despejar previamente el suelo general de violencia que por tantos años constituyó la "norma" de nuestras vidas. En otras palabras, se tiene que haber iniciado antes, en algún momento, quizá incierto, un proceso de deslegitimación de la violencia, para que ahora podamos formular con claridad esta pregunta. Si ahora, la violencia -incluida la de sexo-género- "se ve" o "se ve más" es porque se están forjando los mecanismos de su desnaturalización (esto dicho con precaución y conociendo plenamente la insuficiencia de nuestras bases de datos y de las estadísticas que manejamos). 
Con todo, resalto la importancia de las condiciones a partir de las cuáles ciertas preguntas pueden ser formuladas. En otras palabras, me refiero a la importancia de lo que casi kantianamente se puede denominar "las condiciones de posibilidad de ciertas preguntas" o, a la manera de Castoriadis, "las condiciones de lo pensable". En todo caso, se trata de la toma de conciencia de que ciertos factores histórico-sociales favorecen y/o habilitan algunas preguntas que otrora no podían siquiera plantearse. En efecto, nuestra pertenencia a países cuyas vidas democráticas se han visto drástica y sistemáticamente interrumpidas, promueve cierto desinterés o descuido - por sobresaturación- a la hora de examinar los modos más sutiles y no obvios de la violencia. En realidad, porque qué es "obvio" y "evidente" para una sociedad dada presupone la construcción colectiva de una cierta sensibilidad (y de "control" social), más allá de algunos casos de entrenada hipersensibilización, producto de la experiencia, la militancia o la introyección de las teorías.

En suma, recién ahora podemos examinar lo que Butler denomina el ethos colectivo que, por cierto, suele ser bastante conservador (Butler, 2005, 4). Por un lado, esto significa, que lo que alguna vez fue una idealización normativa dejó de serlo y ya no es creíble, forzándonos a reflexionar sobre el modo en que algunos "estilos de vida" pasan a ser leídos como modos violentos de disciplinamiento, exhibiéndose así la tensión que comienza a generarse entre "los hechos" y "las normas". Por otro, muestra cómo en el marco general de los procesos de desnaturalización de tales normas, se exhiben los límites extremos de la no-visibilización habitual de la violencia. En otras palabras, los grupos que sostienen un cierto ethos colectivo apelan a diversos modos de violencia para reforzar la (aparente) normalidad de sus normas. Estas normas rigen el entretejido social y los modos en que, directa o indirectamente, ciertos individuos se benefician de ellas. Esta situación responde a lo que Butler denominó un ethos anacrónico (Butler, 2005, 5), a mi juicio, refuerza las formas encubiertas y justificadas de violencia. La paradoja consiste precisamente en que el anacronismo de las normas en juego persiste -con fuerzaen el presente. Es decir, se convierte en "algo" del presente bajo la pretensión de constituir un orden normal, como un modo de encubrir los cambios, las resignificaciones y los nuevos estilos. Se trata de la manera en que la violencia implícita, muchas veces 
simbólica, promueve sus efectos explícitamente violentos, a partir de las tensiones y divergencias entre los intereses particulares y los grupales.

Desde luego, tanto el ethos anacrónico como sus resignificaciones se tensan actuados por "variables emergentes singulares" o, en un vocabulario más tradicional, los "individuos". En términos próximo a los usos cotidianos, la "variable individual" remite a un sujeto (o individuo) que actúa y resignifica su situación. Situación que, de hecho, cada quien vive según sus posibilidades y deseos, en tanto cuerpo sexuado. Tal sujeto, se apropia (es decir, selecciona, actúa, acepta, niega, etc.) las leyes y las normas sociales al vivirlas de una cierta manera. Sin ignorar la existencia de ciertas condiciones sociales (más amplias, más circunscriptas, etc.), bajo las cuales esa apropiación se hace posible, lo que implica muchas veces un ethos, de por sí violento, al actuarlas performativamente se hace responsable individual de ellas. En esta apropiación, que necesariamente cada emergente singular (cada individuo) hace del ethos colectivo, tal sujeto adopta (y adapta) deliberadamente un estilo determinado que va desde la persuasión y el disciplinamiento, por un lado, a las formas desbordadas de violencia, por otro; siempre con la intención de alcanzar un fin deseado. Cuando así lo hace, incorpora performativamente para sí alguna variante del refrán popular "el fin justifica los medios". De modo que el "yo" se apropia de las normas morales en tanto las vive, condicionado a su vez por esas mismas normas y estableciendo, a la par, su viabilidad como sujeto (Butler, 2005, 9). Las normas se internalizan, paradójicamente, en tanto mecanismos psíquicos del poder (Butler, 1997, 2) y conformando así los sistemas de creencias de un sujeto dado, quien actúa en consecuencia. Con esto quiero marcar la importancia de las "condiciones de emergencia" del sujeto violento, y en cada caso la importancia de la variable individual. En principio, estructuralmente, las políticas públicas (y sus responsables) tienen el deber éticopolítico de incidir en la modificación de las condiciones violentas de emergencia; es decir, de limitar la posibilidad de adoptar conductualmente resoluciones violentas ante los conflictos que se les presenten, sin que con esto desestimemos las decisiones individuales. 


\section{3- Pasadizos y retículas}

Pues bien, respecto de la violencia cruenta, sabemos que el lugar, el "ahí" de su ocurrencia, es paradigmáticamente el cuerpo de las mujeres (o cuerpos en situación de feminización). El fin (o fines) de quienes actúan bajo un ethos anacrónico, sea por acción, omisión o encubrimiento, es la defensa, conservación y refuerzo de una estructura de sociedad sexista y patriarcal, con todas las consecuencias que conocemos. Grosso modo, ante la hipotética pregunta de "¿quién/es desean sostener un ethos anacrónico?" aún se señala sin más a "los varones". De hecho las estadísticas mundiales (abrumadoras) así parecen corroborarlo, a pesar de que haya casos en los que las mujeres asumen un "arquetipo viril", por utilizar la clásica denominación de Amparo Moreno. Pienso, por ejemplo, en las fotografías vejatorias de ciertas shemarines, que todas recordamos, que recorrieron el mundo. Esos casos nos alertan sobre la importancia de la variable singular o modo en el que cada quién asume el ethos colectivo. Por eso, siempre es pertinente preguntar cuáles varones y por qué.

Convengamos a priori, que en los casos de los titulares citados al inicio de estas reflexiones (y similares), las excusas que registran los expedientes judiciales en su transcripción de las declaraciones de los imputados no dan muestra de razones suficientes que justifiquen el grado de violencia que se les imputa. La mayor parte de las veces se trata de motivos o racionalizaciones a posteriori sin mayor consistencia. Si bien esas excusas podrían examinarse metódicamente, a fin de explorar la psicología de los maltratadores -arrojando buena luz sobre este tipo de problemas- no es ese mi objetivo. No obstante llamo la atención sobre el hecho de que excusas ahora señaladas como inaceptables, han sido consideradas suficientes por siglos y aún muchas veces los periódicos las recogen como dignas de ser tenidas en cuenta, sobre todo si ponen en cuestión la moral de la víctima.

Por su parte, también es verdad que muchos varones golpeadores tienen un perfil que puede describirse como "violento" o "psicopático" pero, una vez más, me interesan las cuestiones estructurales y prefiero indagar sobre otro orden de cosas, no vinculado necesariamente con el perfil de cada sujeto varón singular. En principio, considero importante tener en cuenta el ethos 
anacrónico, en sus particularidades idiosincrásicas. Asimismo, merecen examinarse las tensiones y resistencias que se generan ante la multiplicidad de situaciones (planeadas o no) que alteran ese ethos. Ambos factores ponen en marcha la afirmación sartreana de que lo que no se consigue por la "fuerza de ley" se obtiene por la violencia.

Qué se quiere obtener es, pues, una pregunta pertinente. En parte, ya la he respondido: se quiere obtener que la naturalización del ethos anacrónico -otrora idealizado e incuestionable- no se quiebre, ni pierda vigencia ni rigor. ¿Por qué? Porque la mayoría de los varones ejerce (y se beneficia de ello, lo quiera o no) algún tipo de violencia sobre las mujeres, en principio, en términos estructurales y simbólicos (Femenías, 2008, 47). Pues bien, tal como bien lo señaló Iris M. Young a comienzos de la década de los ochenta $(1983,130)$, la relación entre varón y mujer no debe inscribirse en el ámbito psicológico porque disminuye las posibilidades de comprensión y explicación del verdadero problema, en nuestro caso, el de la violencia. Para esta estudiosa, la relación entre varón-mujer es política y de dominación. Presupone, por tanto, algún modo de ejercicio del poder y se vincula con la noción de supraestructura (en este caso, patriarcal) que no depende de individuos singulares salvo como variable de ajuste. Es decir que, en tanto supraestructural, -continúa Young- depende de un nivel material que rara vez se tiene en cuenta. Esto significa que los varones se apropian, en principio, de beneficios concretos en términos de bienes y servicios que toman de las mujeres. Pero además, como en toda estructura de dominación, hay beneficios de orden simbólico. Como toda supraestructura, la patriarcal se asienta en una ideología, para el caso, patriarcal, lo que implica niveles simbólicos de legitimación de ese orden, en términos de mitos, conceptos explicativos, socialización de los afectos y del deseo, transmisión de los saberes, etc. Es decir que, si bien la teoría psicoanalista feminista (Flax, Dinnerstein) abrió espacios explicativos ricos e inexplorados, que toman en cuenta la experiencia de las mujeres y su comportamiento, esto no es suficiente. A juicio de Young, "la personalidad generizada" depende en mayor medida de la "teoría de la dominación masculina en base a un sistema de sexo-género" (noción que toma de Gayle Rubin) que de los individuos involucrados $(1983,131)$. De modo que, 
la noción de "masculinidad abstracta" de Nancy Hartsock (133) le permitió identificar en el plano ideológico del patriarcado los elementos simbólicos en los que varones y mujeres están aprisionados. Pero, por sobre todo, le permitió subrayar el peso que tienen las instituciones sociales a la hora de determinar no solo las relaciones de clase sino también las de género; sobre todo, lo que se considera "natural" en términos de "permitido" (aceptado) entre ellas y las características "naturales" de varones y de mujeres. Es suma, sobre la base de esta violencia estructural se inscriben todos los demás ejercicios de violencia, que incluyen su forma física, cruel y extrema. En síntesis, la agresión contra las mujeres no es obra ni de varones enfermos ni con trastornos de personalidad, ni de individuos que desatan sus odios bajo los efectos del alcohol u otras sustancias tóxicas. Se trata de personas consideradas normales, que deciden recurrir a la agresión para conseguir el objetivo que desean alcanzar: controlar y someter a una mujer en particular y, a través de ella, a todas las mujeres en general como modo de ejercicio de poder.

Leo nuevamente algunos titulares de periódicos:

La mató de 17 puñaladas... La mató de 113 puñaladas...

La mataron a golpes y patadas... La mató/aron después de violarla y quemarla con...

Enterrada viva después de ser violada repetidas veces...

Violador serial ataca de nuevo... El padre abusó de ella durante 20 años...

etc. etc...

Nuevamente, para explorar algunas líneas que iluminen el problema de la violencia contra las mujeres tal y como se nos presenta actual y cotidianamente, haciéndome cargo de la necesidad de distinción, tengo presente lo dicho hasta ahora y exploro otra sugerencia de Sartre: quien ejerce un acto violento quiere todo inmediatamente y elige conscientemente en consecuencia. En lo que sigue voy a explorar algunas relaciones vinculadas, primero, a la globalización y la crisis, segundo, a los modos en que los varones violentos buscan restaurar su autoestima en el marco de las estructuras actuales de poder, que lo habilitan a ello, apelando a 
lo que he denominado "la herida narcisista del patriarcado". Por último, haré algunos comentarios generales sobre el disciplinamiento.

\section{a- Globalización y crisis}

Sabemos que toda sociedad manifiesta algún tipo de mística femenina, de culto a lo materno o a lo femenino virginal, de modo que cualquier ruptura de ese orden estatuido y naturalizado en términos de sexo-binario y estereotipos sexuales opera como una amenaza a la integridad masculina (Segato, 2003,132). Estas tramas simbólicas se sostienen en el marco general de lo que Iris $\mathrm{M}$. Young denominó "una metafísica general de la ideología" patriarcal, que impone estructuralmente una normalidad, sobre la que sobresale el acontecimiento violento (Femenías, 2008, 29).

Ahora bien, la forma actual de violencia contra las mujeres parece vincularse a la aparición de un acontecimiento novedoso: la globalización. Celia Amorós interpreta la globalización a partir de tres fenómenos convergentes: el paradigma informacionalista, la sociedad en red y el nuevo modelo de desarrollo capitalista. Estos tres fenómenos desestabilizan el modelo decimonónico anterior y los lugares naturalizados que ocupaban en él los individuos, varones y mujeres (Amorós, 2008, 86). La quiebra y transgresión del paradigma decimonónico desnaturalizado pone en crisis por supuesto su modelo económico-laboral, pero también el conceptual y el ético, que proporcionaban los criterios estándar de selección e interpretación de las normas/leyes del ethos vigente, en vías de anacronismo. Es decir, la retícula conceptual que generaba las condiciones de su aceptación, modelando interpretaciones, explicaciones y estableciendo un "qué hay que hacer" en cada caso, entra en crisis.

Los cambios promovidos por la globalización están desestructurando ese ethos volviéndolo rápidamente anacrónico y, en consecuencia, abriendo un vacío de reglas o normas claras, fijas y estables. Una consecuencia es la desnaturalización de las estructuras y de los lugares de emergencia de los sujetos; otra es la pérdida de confianza ante el futuro, dada la carencia de "recetas" sobre qué hacer ante circunstancias altamente novedosas. No hay respuestas, no hay lugares, no hay certezas (Femenías, 2007, 141). 
Por razones de espacio, no puedo extenderme en esto, pero lo cierto es que ante la desarticulación de la esfera del trabajo (la volatilidad de los capitales mundiales, la crisis financiera, etc.), lo que se ha puesto severamente en crisis es la figura modélica del siglo XIX del "varón proveedor". No se trata tanto de que las mujeres hayamos accedido al campo laboral-profesional y a la esfera pública, cuanto que el trabajo tradicional se ha precarizado (pulverizado) para adquirir un perfil próximo al de las variables del trabajo doméstico (Amorós, 2008, 25). Un ejemplo paradigmático actual es el trabajo free lance y los denominados "contrato basura". En la mayoría de los casos, se trabaja en casa, no tiene horarios fijos, ni vacaciones, ni feriados, no incluye beneficios laborales por nacimiento, ni pago de indemnizaciones, ni licencias de salud o maternidad, etc. etc. Tras un siglo y medio de luchas laborales y finalmente el logro de cierto reconocimiento patronal de la figura del "obrero", el "trabajador", el "empleado" o similares, estas figuras se vuelven -debido a la globalización- anacrónicas. En efecto, la globalización ha prácticamente licuado las coberturas legales, los retiros de la tercera edad, los beneficios en salud, etc.

En mayor o en menor medida la nueva situación afecta a todos e incide fuertemente en la autoestima de los varones, cuya identidad se ha centrado desde el siglo XIX en su valor como trabajador y proveedor (omnipotente), tras el "invento" de la familia nuclear. Por eso, así como se debilitan las bases económicas de la sociedad, se debilita también la familia tradicional, la sociedad civil y la ciudadanía, ancladas aún en el modelo burgués de la dicotomía público-privado. La globalización promueve modos de exclusión; más aún de desconfirmación identitaria y los sujetos varones son extremadamente vulnerables a ambos. Esto significa que no pueden cumplir sus expectativas de reconocimiento (al menos en la medida de sus deseos) y cada vez más ocupan una "posición mujer". Este acelerado cambio social, de usos y costumbres, de ley consuetudinaria, de fuga de espacios habituales de reconocimiento, de surgimiento potencial aún de otros nuevos más allá del ámbito doméstico y de los cánones tradicionales, constituye especialmente para los varones una amenaza a su integridad y un eje inconsciente de preocupación, que se expresa de diversos modos: chistes, objetuación y fragmentación del cuerpo de las mujeres, insultos y, por cierto, violencia explícita y cruenta. 


\section{b- En búsqueda de la restauración de la autoestima}

¿Por qué la violencia cruenta? ¿Por qué - me pregunto- varones históricamente construidos como "superiores" habrían de aceptar ese lugar de mayor pobreza, inestabilidad, carencia de reconocimiento, etc., que son los síntomas actuales de la "posición mujer"?. Provisoriamente, propongo trabajar sobre la hipótesis general de que los varones -a partir de los cambios señaladosestarían dispuestos a disciplinar con mayor ahínco a las mujeres, porque las ven como amenaza inmediata (¿inconsciente?) debido a "sus logros" (ignorando el fenómeno de feminización de la pobreza, por ejemplo). Es claro que entienden a las mujeres como eje de "sus" males y sus competidoras "recienvenidas" al mercado del trabajo remunerado. Pero, sobre todo, estas mismas mujeres se han constituido de forma real o imaginaria en sus pares en la búsqueda de reconocimiento. $Y$, en buena medida, como el reconocimiento se ha mercantilizado, esto se mide también en términos económicos según las leyes del mercado. Es otras palabras, los varones sensibilizados a los cambios que los desplazan del eje central del sistema patriarcal hacia la periferia (es decir, hacia la "posición mujer", detectan y rechazan fuertemente el nuevo modo de usufructo paritario de las reglas de la economía libidinal subyacente.

\section{c- Patriarcado y herida narcisista}

La estructura tradicional descripta a grande rasgos se tensa paradojalmente: ¿Qué desea quien desea un "objeto" al que destruye en su deseo? En una dialéctica del reconocimiento, ¿cómo reconstruir la autoestima patriarcal, cuando se destruye violentamente a quién debería repararla? ¿No será que a las tradicionales heridas narcisistas de la sociedad occidental -que tan bien (y patriarcalmente) desplegó Freud- habrá que agregar otra? Muy acertadamente, la psicóloga Liliana Fedullo señala que “... la compulsiva consumición/ apropiación, recuerda el proceso de identificación canibalística del agresor", tal como la expone el mismo Freud en Tótem y Tabú, apropiándose de las facultades de la/s otra/s personas (Fedullo, 2009, 2). Dominio, soberanía, control y colonización operan como el universo de significación 
de la violencia masculina y alimentan su virilidad; es decir, su autoestima. El desprecio a lo femenino, en general, es el componente preponderante en la agresión. La víctima es el desecho, la pieza descartable, porque la impunidad garantiza el dominio de la cofradía por sobre la voluntad del sujeto. Al mismo tiempo, para cada varón en particular, esa apropiación simbólica del “lugar" y de las "particularidades recién adquiridas" de las mujeres restaura (transitoriamente) su autoestima, reforzando en tiempo presente el orden anacronizado. Pero, a la vez, consumiendo, destruyendo, su "objeto"; es decir, el único sujeto que en verdad puede reconocerlo.

En suma, una consecuencia posible e indeseada de esta crisis de la identidad patriarcal, además de la ruptura del ethos moderno -que fractura y desplaza la dupla inferior-superior- es la quiebra de la previsibilidad de la posición como "variable vacía" para un sujeto emergente dado. El lugar de inscripción de los sujetos ya no depende solo del sexo (o del color de la piel) en términos de adjudicación inmediata del lugar "superior" o "inferior". Incluso, cuando así se lo enuncia, esto es políticamente incorrecto y éticamente impugnable. Cada vez más varones vienen a poblar los espacios abyectos del "inferior", carente de reconocimiento y de poder para sellar -en la complicidad del pacto-su lugar como superior (Fedullo, 2009, 2). Esta situación parece abrir entonces una suerte de "herida narcisista" en el patriarcado que, desde las décadas finales del siglo XX, descarga contra las mujeres "un ritual de sacrifico, violento y macabro", a manera de reconvención disciplinaria del objeto (insubordinado) de deseo.

De manera que interpreto esta nueva violencia contra las mujeres (tanto simbólica cuanto cruenta) como una estrategia de reafirmación de la propia identidad patriarcal (en términos de virilidad) "superior", su redefinición y reacomodamiento simbólico-funcional de los miembros varones más débiles en virtud de su auto-reconocimiento psicoidentitario. Así, la violencia cruenta -y su expresión extrema de violación, mutilación y asesinato de mujeres- "funciona" como un modo de "castigo" o "admonición" reparatorio de la autoestima del varón, en términos psicoestructurales, quien en el mismo acto de agredir fagocita (simbólicamente) las facultades deseadas y, a la vez, disciplina, castiga o reconviene al inferior, en un intento por restaurar un orden jerárquico "natural”, en disolución, de "su" mundo. 
Esa violencia, además, está implícita en los modos en que estructuralmente se construyen los vínculos varón-mujer. Históricamente, se trata de la naturalización de los "otros" como interiores (las mujeres, los negros, los pueblos originarios, etc.) que, desplazados "hacia arriba" de sus lugares "naturales" generan siempre reacciones que van desde el desconcierto a la violencia.

\section{d- El deseo y sus disciplinas}

La carga libidinal a la que someramente he apuntado más arriba permite dar cuenta de la intransigencia del violento, que solo afirma su derecho (patriarcal-divino) como persona humana a tener todo que quiere inmediatamente, donde "el otro mujer" solo es un obstáculo denso, aunque inesencial, entre él y su objeto de deseo (ser reconocido como superior sin más), entendido como el "fin" a alcanzar. En el fondo, el violento pretende despejar los obstáculos que supuestamente lo separan de -o le esconden- tal objeto. En cierto sentido, el violento cree en el orden natural del mundo y en la necesidad de restituirlo. En la situación actual, "su" lugar en el mundo se le presenta disimulado o escamoteado por obstáculos que debe suprimir a fin de que ese orden se restaure y así él pueda volver a alcanzar "su" lugar natural. En ese sentido también, podría decirse con Sartre, que el violento es "un puro" que no acepta ni el fracaso ni el límite. Por tanto, sustituye la posibilidad de alcanzar aunque sea parcialmente algún fin, por la destrucción total de los "obstáculos" que le impiden llegar a ese fin, y con ello, paradojalmente, al "fin", mismo ahora absoluto y magnificado. El "fin" -como marqué más arriba- es restituir su autoestima "poniendo en su lugar" al otro-inferior. Sin embargo, en sentido estricto, tal objetivo del deseo no puede cumplirse puesto que la misma violencia lo consume qua tal. Pero instala, en cambio, una "moral de la violencia". Es decir, una moral que justifica la imposición "del vencedor" (¿qué es si no el "contrato" hobbesiano?). Por eso, cuando la norma consuetudinaria, el uso, la costumbre, la orden que se imparte (entendida primero como "persuasiva") fracasa, no "le" queda sino la violencia explícita de tomar al "la otro/a" en su mera facticidad de objeto interpuesto, mera intermediación o escollo a sortear.

Otra vez, se abre una paradoja: todo acto de violencia es, 
por definición, un fracaso. Un fracaso porque en la destrucción del "objeto" en su facticidad, se destruye a la vez la posibilidad misma de la satisfacción en/con el "objeto" del deseo de reconocimiento. Más allá de los individuos violentos involucrados, las estructuras sociales jerárquicas -hoy más lábiles que nuncapromueven, encubren o favorecen la violencia, en tanto producto de las tensiones entre un ethos anacrónico, la sociedad futura y las elecciones de sujetos emergentes que "eligen" actuar los modos más violentos de restauración de su autoidentidad tradicional en peligro.

\section{4- Conclusiones preliminares}

Retomo algunas breves consideraciones que hacen a las posiciones estructurales de las mujeres. En primer término, en toda sociedad, aunque con características propias, los cuerpos de las mujeres siempre han tenido un valor simbólico adicional, como garantía de sutura de conflictos o como lugar de ejercicio de poder para humillar, deshonrar, negar o enviar mensajes cifrados a otros varones, aunque se lo niegue o ignore. Levantar la prohibición estructural que rige "el lugar" de las mujeres, hace visible el grado de violencia que históricamente ha ejercido esa invisibilización y, a la vez, se constituye en un modo de autorizar una explicación alternativa en términos sistemáticos. Es decir, denunciar el ethos anacrónico y promover la instalación de un nuevo ethos potencia múltiples y diversas resistencias.

Actualmente, las políticas de la identidad favorecen las identificaciones, incluso las anacrónicas, por fuera de los derechos paritarios y de la ciudadanía, lo que contribuye a actualizar el principio -ya mencionado- de que ninguna sociedad trata a sus mujeres tan bien como a sus varones. Este lugar de vulnerabilidad histórica, se refuerza por la fragmentación pública (medios masivos de comunicación) de los cuerpos de las mujeres con fines de su explotación en términos de "cuerpos-objeto" de consumo erótico y/o pseudo-médico-estético. De modo diferente, la explotación laboral en términos de "cuerpos maquila" sub asalariados genera una competencia -entendida como "desleal" - en el mercado de trabajo, con características próximas a las de la economía del trabajo doméstico, pero fuera del hogar, que comparten 
los varones de casi todos los niveles a partir de la globalización y la crisis mundial de la economía. Se producen a partir de la feminización del patriarcado global, un conjunto de resistencias más o menos explícitas que desembocan en nuevas formas de violencia contra las mujeres.

En este contexto, la violencia adquiere un carácter "ejemplificador", "edificante" y portador de los "valores" tradicionales de la disciplina y los lugares naturales. Se la exhibe preferentemente en el espacio público, potenciándose un voyeurismo mediático, en especial televisivo, que refuerza identificaciones en términos de víctima-victimario individual. De ese modo, se confirman las acciones de los "perpetradores", en el marco de lo que tan acertada como anticipatoriamente señaló el artista plástico estadounidense Andy Warhol: "gozar de cinco minutos de fama", eso significa en definitiva, para muchos, estar en los medios.

Que mal se denomine "doméstica" a ese tipo de violencia, constituye además otra doble advertencia. A las mujeres, les muestra los riesgos de (intentar) transgredir -simbólica y colectivamente- su lugar "natural" tradicional-consuetudinario; se trata de la admonición disciplinar con intenciones reparatorias en -como hemos visto- más de un sentido. Para los varones, por su parte, si bien la violencia puede constituir un "fracaso" metodológico, favorece de todos modos una suerte de reconocimiento compensatorio: primero, en términos de publicidad; segundo en tanto su "imagen" y sus "actos" provocan temor, y el temor es uno de los controladores fundamentales de la conducta de las personas. El mensaje ejecutado en una mujer (la "suya"), se dirige a todas las mujeres general y a quienes ocupen, de una forma u otra, una posicionalidad feminizada.

Por último, sea como fuere, en mayor o en menor medida, todos y todas contribuimos a reproducir una visión del mundo que enmascara la violencia simbólica de los varones sobre las mujeres. Por eso, considerar la violencia de género solo como el subproducto de una relación enferma entre un varón y una mujer individuales y determinados, aislándola del marco constitutivo y reproductor de la desigualdad entre ambos y de su socialización, conlleva el peligro de quitar la parte política a lo personal invirtiendo el lema de los sesenta (Soza-Rossi, 2006, 165). 


\section{Notas}

1 Doctora en Filosofía. Académica del Departamento de Filosofía de la Universidad Nacional de La Plata y de la Universidad de Buenos Aires.

2 Cf. también, Fayner, Elsa. Violences, féminin pluriel. París: Document, 2006. Retomo algunas ideas de Femenías, María Luisa y Paula Soza Rossi "Poder y violencia sobre el cuerpo de las mujeres". Revista Sociologías. 21 (2009): 42-65 y Aponte Sánchez, Élida y María Luisa Femenías. Articulaciones sobre la violencia contra las mujeres. La Plata: Edulp, 2008.

3 Tomo libremente algunas consideraciones de Cahiers pour une morale de J. P.Sartre.

\section{Bibliografía}

Amorós, Celia. Mujeres en el imaginario de la Globalización. Rosario: Homo Sapiens, 2008.

Aponte Sánchez, Elida y María Luisa Femenías. Articulaciones sobre la violencia contra las mujeres. La Plata: Edulp. 2008.

Butler, Judith. The Psychic life of Power. Stanford: Stanford University Press, 1997.

----- Giving an account of Oneself. New York: Fordham University Press, 2005.

Fayner, Elsa. Violences, féminin pluriel. París: Document, 2006.

Fedullo, Liliana. "La intemperie simbólica de la violencia masculina" $1^{\circ}$ Congreso Interdisciplinario sobre Género y Sociedad: Debates y prácticas en torno a Violencias de género, Universidad Nacional de Córdoba (Argentina), 27, 28 y 30 de mayo de 2009.

Femenías, María Luisa y Paula Soza-Rossi. "Poder y violencia sobre el cuerpo de las mujeres". Revista Sociologías, 21 (2009): 42-65.

Femenías, María Luisa. El género del multiculturalismo. Bernal: UNQui, 2007.

Osborne, Raquel. "De la 'violencia' (de género) a las 'cifras de la violencia': una cuestión política". Empiria, Revista de Metodología de Ciencias Sociales, Universidad Nacional de Educación a Distancia, 15 (2008): 99-124.

Segato, Rita. Las estructuras elementales de la violencia. Buenos Aires: Prometeo, 2003.

Soza-Rossi, Paula. "La herida está ahí antes que el cuchillo esté ahí: revisando la mirada sociológica sobre la violencia de género". Femenías, María Luisa (comp.) Feminismos de París a La Plata. Buenos Aires: Catálogos, 2006: 163-186. 
Young, Iris Marion. "Is Male Gender Domination the Cause of Male Domination?" Ed. Joyce Trebilcot. Mothering: Essays in Feminist Theory, New Jersey: Rowman \& Allenheld, 1983. 